\title{
Development of a symptom expectation questionnaire for minor head injury
}

\author{
Robert FERRARI ${ }^{\dagger}$, Deon LOUW \\ (Department of Medicine, University of Alberta, Edmonton, Alberta T6G 2P4, Canada) \\ †E-mail: rferrari@shaw.ca \\ Received Mar. 5, 2011; Revision accepted May 3, 2011; Crosschecked May 20, 2011
}

\begin{abstract}
Background and objective: Expectations and beliefs are important predictors of outcome following minor head injury. In this paper, the primary purpose is to develop a simple symptom expectation questionnaire for minor head injury for use in future research studies. Methods: An existing database of 179 injury-naive subjects who completed a 56-item checklist of expected symptoms for minor head injury was analyzed to determine which items could correctly identify an a priori case definition of an expecter (a subject who expected at least one of these symptoms would remain chronic following minor head injury). A total of six of the 56 items were found to be discriminatory, and these were tested in additional subject groups against the original questionnaire. Results: From the original database of 179 subjects completing a 56-item symptom expectation checklist, 135 expected that at least one of the 56 symptoms would be chronic following minor head injury. The 135 expecters, however, all chose at least one of six items: headache, anxious or worried, depressed, difficulty concentrating, dizziness, and neck pain. Using these six items, in two new groups of subjects, all those who endorsed one of the 56 symptoms as likely to be chronic following minor head injury (expecters) could also be identified on the 6-item checklist. Conclusions: A shortened (6-item) symptom expectation checklist of commonly reported symptoms following minor head injury (headache, anxious or worried, depressed, difficulty concentrating, dizziness, and neck pain) correctly identifies subjects who expect that at least one symptom will be chronic following minor head injury (i.e., an expecter).
\end{abstract}

Key words: Minor head injury, Expectation, Outcomes doi:10.1631/jzus.B1100098
CLC number: R651.1 ${ }^{+} 5$

\section{Introduction}

Given the observation that expectations and beliefs are predictors of recovery from minor head injury (Whittaker et al., 2007), there is a need to determine the prevalence of these expectations and beliefs in the general population (i.e., in the injury-naive population). It is this population that is at future risk for developing worse outcomes following minor head injury because of those beliefs, and which may be targeted with social marketing campaigns, such as those used for reducing disability from acute low back pain (Buchbinder et al., 2001). An aspect of beliefs concerns expectations of recovery and particularly the expectation that certain symptoms are likely to be chronic after minor head injury. One study of 179 subjects in Canada, for example, found that 135 of 179 subjects who had never experienced head injury themselves, believed that at least one symptom from an available 56-item symptom checklist would not only occur following minor head injury, but would remain chronic (Ferrari and Lang, 2005). Many subjects chose multiple symptoms as likely to remain chronic, the most commonly endorsed symptoms being related to headache, dizziness, anxiety, depression, problems with concentration, problems with memory, and neck pain.

This 56-item symptom expectation checklist (Ferrari and Lang, 2005) is too cumbersome for clinical and population research purposes. To shorten 
the instrument, but at the same time to maintain a high likelihood of capturing "expecters" (those who would expect at least one symptom to be chronic following minor head injury), it is necessary to develop an instrument that contains cardinal symptoms and at the same time reflects the array of possible beliefs in the population about what minor head injury might do to a victim. Some individuals may think that minor head injury mainly causes chronic pain (e.g., headache) or affects mood or cognitive function. The primary purpose of the current study was to determine from an existing database derived from a 56-item symptom expectation checklist if a much smaller checklist also is likely to capture those individuals who expect at least one symptom following minor head injury will remain chronic.

The research question is: What proportion of the subjects who endorse at least one of the 56 symptoms on a 56-item as likely to be chronic following minor head injury (expecters) will also be identified as expecters using the 6 -item checklist?

\section{Methods}

\subsection{Assessment of the 56-item symptom expecta- tion checklist}

The results of a survey of Canadian subjects for their expectations following minor head injury are used in this study (Ferrari and Lang, 2005). As described in the published study, a 56-item symptom expectation checklist was developed, which included the same items used by Aubrey et al. (1989) and Mittenberg et al. (1992) combined, these latter authors having previously examined symptom expectation in North America without assessment of expectations of chronicity. Using this 56-item symptom expectation checklist, subjects were given a vignette prior to reviewing the checklist:

"Automobile accidents are a fact of life and can happen to anyone. We are interested in your opinion of what symptoms or problems might affect you after an accident. Imagine that you were driving or sitting as a passenger in a car and suddenly another car hit you. Imagine you were knocked out for a while and when you woke up you were in hospital for a few hours to recover then went home. You had no broken bones. Check YES or NO for each of the symptoms you think you might have as a result of the accident. For those you check "YES", check off ONLY ONE time period that best describes for how long you think you would have those symptoms." (Ferrari et al., 2001).

The instrument, as shown in earlier studies, then requires the subject to indicate the symptoms expected, but then also indicate the duration, which allowed us to examine for expectation of acute symptoms and symptoms expected to be chronic.

\subsection{Development of a shortened symptom expec- tation checklist}

From this aforementioned database, a shortened symptom checklist was created. First, it was noted that 135 of 179 subjects chose at least one of the 56 items as being expected not only to occur following minor head injury, but to last for "months to years". These subjects were labeled as having met the case definition of an expecter. The responses of individual subjects were examined to determine the fewest number of items that had to be retained in the checklist to correctly identify each of these expecters. This short list of items (discriminatory items) formed the shortened symptom expectation checklist for further testing.

\subsection{Testing of the shortened symptom expectation checklist}

These discriminatory items were then tested with two groups of 100 subjects each recruited in a fashion similar to the original survey (Ferrari and Lang, 2005) from a local university (students and staff). The subjects were surveyed with both the 56-item symptom expectation checklist and the shortened symptom expectation checklist. One group of 100 subjects was given the 56-item symptom expectation checklist first, then the shortened symptom expectation checklist one week later. The second group of 100 subjects was given these checklists in a reverse order, again one week apart.

Subjects were approached by one individual, and were presented with the instrument, a written statement of the intent of the study, and the exclusion criteria. Data were collected about age, gender, and education level. This was part of a larger study examining beliefs and expectations about a number of conditions, some of which have been published. The 
study protocol excluded those who had a head, facial, or neck injury in a previous motor vehicle collision, or had an immediate family member with such an injury. Originally, we considered excluding any subject who may have known anyone who had these injuries, but since in previous work we found these injuries to be very common, we simply excluded those with a personal experience or immediate family member with such an experience. In this way, most of the subjects were likely to be naive (in terms of direct experience) of the outcomes of these injuries. The inclusion criterion was age 18 or older, and the exclusion criteria were inability to communicate in English, prior head, facial, or neck injury from a motor vehicle collision, or an immediate family member with such an injury.

\subsection{Sample size calculations}

The study relies on existing data and thus no a priori sample size calculations were made.

\subsection{Statistical analyses}

Descriptive statistics are reported regarding the age and gender of subjects. Education levels were also compared between groups. The number of expecters from each survey instrument is reported, an expecter being defined as any subject who endorsed at least one item from the checklist as likely to be chronic following minor head injury.

Individual responses were assessed to determine if subjects who were deemed expecters on the 56-item symptom expectation checklist would also be classified similarly on the shortened symptom expectation checklist, and vice versa.

This study was approved by the Research Ethics Board of the University of Alberta, Canada.

\section{Results}

From the original database (Ferrari and Lang, $2005)$ of 179 subjects (mean age of $(35 \pm 11)$ years, $56 \%$ female) with 135 expecters of the 56 items, six were discriminatory and captured each expecter. That is, all 135 expecters, at the very least, endorsed one or more of these six items: headache, anxious or worried, depressed, difficulty concentrating, dizziness, and neck pain.

A total of 52 of 100 new subjects (mean age of
(32.5 \pm 9.6$)$ years, $52 \%$ female) given the 56 -item symptom expectation checklist were expecters. These 52 subjects were also correctly identified one-week later as expecters on the shortened (6-item) symptom expectation checklist comprised of the abovementioned six items, and none of the responses on the shortened (6-item) symptom expectation checklist identified expecters that were not already detectable from the 56-item symptom expectation checklist.

A total of 49 of 100 additional subjects (mean age of (34.8 \pm 7.8$)$ years, $52 \%$ female) given the shortened (6-item) symptom expectation checklist were expecters. These 49 subjects were also correctly identified one-week later as expecters on the 56-item symptom expectation checklist, and none of the responses on the 56-item symptom expectation checklist identified expecters that were not already detectable from the shortened (6-item) symptom expectation checklist. Education levels were similar between all groups.

\section{Discussion}

This study shows that a previously utilized 56-item symptom expectation checklist can be reduced to a shortened (6-item) symptom expectation checklist, which can still capture those individuals who hold the expectation that head injury is likely to result in chronic symptoms. The shortened (6-item) symptom expectation checklist is comprised of these items: headache, anxious or worried, depressed, difficulty concentrating, dizziness, and neck pain. These are symptoms commonly reported after minor head injury, though the inclusion of chronic neck pain as a commonly held expectation after minor head injury is somewhat surprising. This may result from the commonly held belief that spinal and head injuries often co-exist.

There are limitations to this study. The sample sizes are relatively small, and do not reflect a population-based survey. Nevertheless, the subjects provide a wide range of education levels and both genders are included. Previous studies have found that beliefs about injuries are not generally affected by age, gender, education, or previous injury experience (Ferrari and Russell, 2010).

It is clear that expectations of chronic pain and 
other symptoms after minor head injury are highly prevalent, even in those who have not experienced the disorders before. These findings have direct and important clinical implications. Expectations for type and duration of symptoms exist prior to the injury. Minor head injury is seen in the general public as often having a poor prognosis, frequently leading to chronic symptoms. It seems likely that these prior beliefs are influential in the expectations individuals form for their own recovery after an actual injury (Whittaker et al., 2007); and that these expectations for recovery are modified by the immediate injury experience (for example initial pain intensity and extent), as well as by early experiences with health care professionals.

The findings of this study suggest that it is worthwhile to consider population-based surveys of expectations and beliefs following minor head injury and a shortened (6-item) symptom expectation checklist can serve this purpose. As the expectations become known on a population level, social marketing campaigns can be considered, knowing the prevalence and pattern of these expectations. This shortened (6-item) symptom checklist could be used in clinical practice to identify those who expect their minor head injury will lead to chronic symptoms, and can also be used in research studies examining expectation as a predictor of outcome.

\section{References}

Aubrey, J.B., Dobbs, A.R., Rule, B.G., 1989. Laypersons' knowledge about the sequelae of minor head injury and whiplash. J. Neurol. Neurosurg. Psychiatry, 52(7):842846. [doi:10.1136/jnnp.52.7.842]

Buchbinder, R., Jolley, D., Wyatt, M., 2001. Population based intervention to change back pain beliefs and disability: three part evaluation. BMJ, 322(7301):1516-1520. [doi: 10.1136/bmj.322.7301.1516]

Ferrari, R., Lang, C., 2005. A cross-cultural comparison between Canada and Germany of symptom expectation for whiplash injury. J. Spinal Dis. Tech., 18(1):92-97. [doi: 10.1097/01.bsd.0000138214.70260.91]

Ferrari, R., Russell, A.S., 2010. Correlations between coping styles and symptom expectation for whiplash injury. Clin. Rheumatol., 29(11):1245-1249. [doi:10.1007/s10067010-1443-1]

Ferrari, R., Obelieniene, D., Russell, A.S., Darlington, P., Gervais, R., Green, P., 2001. Symptom expectation after minor head injury. A comparative study between Canada and Lithuania. Clin. Neurol. Neurosurg., 103(3):184-190. [doi:10.1016/S0303-8467(01)00143-3]

Mittenberg, W., DiGiulio, D.V., Perrin, S., Bass, A.E., 1992. Symptoms following mild head injury: expectation as aetiology. J. Neurol. Neurosurg. Psychiatry, 55(3):200204. [doi:10.1136/jnnp.55.3.200]

Whittaker, R., Kemp, S., House, A., 2007. Illness perceptions and outcome in mild head injury: a longitudinal study. $J$. Neurol. Neurosurg. Psychiatry, 78(6):644-646. [doi:10. 1136/jnnp.2006.101105] 